\title{
Representações sociais do crack na imprensa pernambucana
}

\section{Social representations about crack in the Pernambuco press}

\author{
Maria de Fátima de Souza SANTOS \\ Manoel de Lima ACIOLI NETO \\ Yuri Sá Oliveira SOUSA
}

\begin{abstract}
Resumo
Este artigo teve como objetivo analisar as representações sociais sobre o crack veiculadas pelos jornais pernambucanos. O trabalho caracterizou-se como uma pesquisa documental, com base na análise de 283 matérias publicadas em jornais de ampla circulação na cidade do Recife, no período de janeiro de 2007 a abril de 2008. Os dados foram analisados por meio do software Alceste e da análise de conteúdo. Os resultados demonstraram que os discursos veiculados sobre o crack, por um lado, descrevem-no como uma droga relacionada a uma forte angústia e fragilidade do sujeito, e, de outro, como parte do narcotráfico, relacionando-o com a criminalidade. Essas representações, portanto, devem ser observadas, pois a elas podem estar associados discursos e práticas sociais que situam o usuário como sujeito desprovido de capacidade avaliativa de sua própria condição e de sua relação com a droga, podendo-se recair em práticas paternalistas e/ou violentas com os usuários.
\end{abstract}

Unitermos: Crack. Política pública. Representação social. Violência.

\begin{abstract}
The aim of this article was to analyze social representations about crack circulated by newspapers in Pernambuco. The study is characterized as a documentary research, based on the analysis of 283 articles published by two widely circulated newspapers in Recife from January 200 to Abril 2008. Data were analyzed using the Alceste software program and content analysis. The results demonstrated that the information circulated about crack, on one hand described it as a drug related to the subject's strong anguish and weakness, and on the other, as part of drug trafficking, relating it to crime. These representations should therefore be observed as they may be associated with social discourses and practices that place drug users as subjects lacking the capacity to evaluate their wn condition and relationship with the drug, and one could lapse into paternalistic and orviolent practices towards the users.
\end{abstract}

Uniterms: Crack. Public policy. Social representation. Violence.

O crack é, atualmente, um dos psicoativos de uso crescente na sociedade pernambucana, penetrando cada vez mais na classe média e sendo associado, pela opinião pública, como fator desencadeante de agressividade e violência. Constantemente a imprensa discute o consumo do crack, o que parece demonstrar uma preocupação social quanto aos efeitos que ele pode causar tanto do ponto de vista da saúde individual, quanto de seus impactos sociais. Nesse sentido, o intuito deste estudo foi compreender como o fenômeno vem sendo veiculado pela imprensa escrita e, assim, analisar as representações sociais que estão a ele relacionadas.

$\operatorname{rrth}$

1 Universidade Federal de Pernambuco, Centro de Filosofia e Ciências Humanas, Departamento de Psicologia. Av. Prof. Moraes Rego, 1235, Cidade Universitária, 50670-901, Recife, PE, Brasil. Correspondência para/Correspondence to: M.F.S. SANTOS. E-mail: <mfsantos@ufpe.br>. 
O consumo abusivo de crack está relacionado a diversos problemas de ordem física, psiquiátrica e social. No mundo, estima-se que entre 14 e 20 milhões de pessoas sejam usuárias da substância (United Nations Office on Drugs and Crime, 2011). No Brasil, de acordo com o II Levantamento Domiciliar sobre o Uso de Drogas, realizado pelo Centro Brasileiro de Informações sobre Drogas (CEBRID) (Carlini et al., 2007), constatou-se que 3,2\% dos indivíduos do sexo masculino, entre 25 e 34 anos de idade, já usaram a droga. Dados epidemiológicos recentes mostram que seu consumo vem crescendo entre os estudantes do ensino médio e fundamental (Galduróz, Noto \& Carlini, 1997). No V Levantamento Nacional sobre o Uso de Drogas entre crianças e adolescentes entre 10 e 18 anos, vivendo em situação de rua nas 27 capitais brasileiras, realizado pelo CEBRID (Galduróz, Noto, Fonseca \& Carlini, 2005), verificou-se que o uso frequente de crack foi mencionado na maioria das capitais. Os maiores índices ocorreram em São Paulo, Recife, Curitiba e Vitória, variando entre 15,0\% e 26,0\%. Segundo Duailibi, Ribeiro e Laranjeira (2008), o crack começou a ser utilizado no final dos anos de 1980, especialmente nos estados das regiões Sul e Sudeste, por crianças e adolescentes em situação de rua. Observa-se, portanto, que os problemas derivados de substâncias psicoativas, tanto aqueles relacionados ao tráfico quanto às consequências individuais e coletivas do consumo, estão inseridos no cotidiano das pessoas (Toscano Jr., 2001).

A relação com substâncias psicoativas não é algo recente na humanidade. MacRae (2001) descreve que, desde a pré-história, plantas e algumas substâncias de origem animal são utilizadas para alterar a consciência com inúmeros fins. É interessante observar que os sentidos atribuídos ao uso de psicoativos sofrem variações segundo o meio cultural em que se insere: objeto de rito sagrado, artigo de cura e prática hedonística são algumas das principais motivações para seu consumo. Bucher e Lucchini (1992) afirma que a droga não existe excluída da experiência, pois seria a atividade simbólica em relação ao conjunto motivacional do consumidor que permitiria denominar uma substância como psicoativa. Para o autor, o usuário é um sujeito ativo que, como todo ser humano, utiliza símbolos para se comunicar. Então, esses elementos simbólicos são significados como um processo de constante reformulação, alterando-se sempre que esse sujeito interagir com seu

380 ambiente.
O consumo de cocaína, por exemplo, teve origem no altiplano andino há mais de 4500 anos, como afirmam Ferreira e Martini (2001). Os autores salientam que existem várias lendas em que a droga é associada aos mistérios da fertilidade, da sobrevivência e da morte, assim como a práticas curativas. Oliveira (2007) descreve que seu consumo era buscado pelo efeito estimulante da substância, amenizando fome e fadiga e proporcionando bem-estar e energia. Além disso, ainda tinha propriedades curativas, sendo, por isso, considerada portadora de virtudes mágicas entre os indígenas, recebendo posição de destaque em sua vida social e religiosa. Os Incas consideravam a Erythroxylon coca uma dádiva de Inti, o deus-sol. Seu consumo era privilegiado e, portanto, restrito aos representantes da nobreza, até o momento da invasão espanhola. Durante o período colonial, aconteceu uma disseminação do consumo entre o restante da população. No Brasil, as etnias indígenas localizadas na fronteira com a Venezuela mantiveram o hábito de mascar a folha, conhecida como "epadu" ou "ipadu", assim como de inalar um pó preparado com as folhas torradas misturadas a elementos alcalinos (Ferreira \& Martini, 2001).

Dentre os Tucanos, uma dessas etnias brasileiras, os idosos ingeriam o pó diversas vezes ao longo do dia, com colher de osso, buscando bem-estar e euforia, além de nutrição para o cumprimento das tarefas cotidianas. Contudo, eles demarcavam um limite à quantidade de folhas mascada por uma pessoa, como precaução contra a intoxicação. A estimativa média de consumo era de $60 \mathrm{~g}$ de folha mascada por dia, o equivalente a $200 \mathrm{mg}$ a 300mg de cocaína, sendo seus efeitos similares ao de muitas doses de cafeína.

Inicialmente, os hispânicos consideraram essa atividade como uma prática cultural, interpretando-a como um empecilho para a difusão do cristianismo, portanto uma prática que deveria ser interditada. Essa proibição, entretanto, foi logo abolida e, em seguida, a coca foi introduzida na Espanha, onde passou a ser usada com fins medicinais. Durante o período pré-colombiano, se existiam efeitos danosos, eles não eram notados (Ferreira \& Martini, 2001).

Somente no século XIX, com a revolução industrial, é que o princípio ativo da folha foi extraído, iniciando as repercussões sobre seu consumo excessivo e inserindo na sociedade europeia uma nova substância (MacRae, 2001). Naquele momento, sabia-se que a nova 
substância era derivada de uma planta e que ajudava a diminuir a dor. O que ocorria era uma manifestação do hedonismo em muitas pessoas, que acabavam por utilizar a substância para vivenciar momentos de prazer. Oliveira (2007) afirma que, no início, a cocaína era utilizada sem nenhuma prescrição ou regulação legal, e que sua venda e consumo eram livres, estando presentes inclusive em farmácias, mercearias e bares. No Brasil, sua venda era livre, existindo até mesmo a entrega em domicílio, pelas farmácias.

Atualmente, o uso da cocaína persiste como uma realidade, com ainda mais poder de ação psíquica devido às novas substâncias sintetizadas, como o crack. Entretanto, as novas práticas parecem atribuir novos sentidos a essas substâncias. Desse modo, o uso da cocaína já não possui o mesmo significado daquele originado nos Andes. Se por um lado, a cocaína é valorizada pelos grupos que a consomem, por outro lado, ela é concebida por outros grupos como causa de violência e de problemas individuais e familiares. Deve ser ressaltado, entretanto, que a cultura do crack tem sofrido mudanças quanto ao padrão de uso. Embora a maioria dos usuários o faça de forma compulsiva, observou-se a existência do uso controlado (Oliveira \& Nappo, 2008). Objeto de polêmica, o crack assume sentidos diversos em função dos grupos sociais que com ele se relacionam. Inserido nas práticas cotidianas e objeto de comunicação entre os grupos, pode-se afirmar, portanto, que o crack é, atualmente, um objeto de representação social.

Como uma forma de saber, as representações sociais permitem aos indivíduos compreender e explicar a realidade, construindo novos conhecimentos. Ao integrar um novo conhecimento a saberes anteriores, faz do novo algo assimilável e compreensível. Elas têm por função, também, situar os indivíduos e os grupos no campo social, permitindo-Ihes a elaboração de uma identidade social e pessoal gratificante (Almeida, 2005).

Moscovici (2003) concebe as representações sociais como estruturas dinâmicas, que operam em um meio de relações e comportamentos que estão em constante alteração, junto com as representações. Sua preocupação é compreender a sociedade atual: seu plano político, científico e humano.

Nossas coletividades hoje não poderiam funcionar se não se criassem representações sociais baseadas no tronco das teorias e ideologias que elas transformam em realidades compartilhadas, relacionadas com as interações entre as pessoas que, então, passam a constituir uma categoria de fenômenos à parte (Moscovici, 2003, p.48).

Santos (2005) explica que essas teorias são conjuntos de conceitos advindos das práticas sociais, que têm como função atribuir sentido à realidade social, além de produzir identidades, organizar as comunicações e orientar as condutas. Dessa forma, o que se propõe com as representações sociais é uma "análise das formas culturais de expressão dos grupos, na organização e transformação dessa expressão, além da análise de sua função mediadora entre o indivíduo e sua sociedade" (Santos, 2005, p.23).

As representações sociais são construídas nas práticas sociais ao mesmo tempo que as orientam. Elas são constitutivas da realidade social. "Concretamente, significa dizer que as representações sociais têm a capacidade de criar e de estipular uma realidade denominando, objetivando noções e imagens, dirigindo as práticas materiais e simbólicas para esta realidade que lhes corresponde" (Moscovici, 2003, p.96).

Assim, as representações sociais são importantes porque guiam o modo de nomear e definir conjuntamente os diferentes aspectos da realidade cotidiana, interpretando-os e possibilitando tomar decisões e posicionar-se diante deles. Elas podem ser observadas em múltiplas ocasiões, visto que circulam nos discursos, são veiculadas em mensagens e imagens midiáticas, e cristalizadas em condutas e organizações materiais e espaciais (Jodelet, 2001). Nessa perspectiva, este estudo visou investigar as representações sociais de crack veiculadas nos jornais impressos do estado de Pernambuco.

\section{Método}

Esta é uma pesquisa documental na qual foram analisadas 283 matérias veiculadas, num período de 1 ano e 4 meses (janeiro de 2007 a abril de 2008), pelos dois jornais de maior circulação do estado de Pernambuco, que possuíssem referência ao crack. As matérias foram coletadas em seu formato eletrônico utilizando-se crack como palavra-chave.

Os dados foram analisados com o apoio do software Alceste, versão 4.9 (Image, Toulouse, França), que analisa a coocorrência das palavras nos enunciados, para organizar e sumariar informações consideradas relevantes. Sua base metodológica está na conceituação 
léxica. Esse tipo de tratamento pressupõe que o uso de vocabulários distintos pode detectar maneiras diversificadas de pensar sobre um determinado objeto (Nascimento \& Menandro, 2006).

O Alceste realiza uma análise estatística automática e, a partir do cálculo de fragmentos do texto em classes lexicais, produz uma Classificação Hierárquica Descendente, apresentada em forma de um dendrograma. O software oferece ainda trechos dos discursos nos quais as palavras que formam as diferentes classes estão inseridas. Assim, com base nos resultados da Classificação Hierárquica Descendente foi realizada uma análise qualitativa, buscando-se reconstituir os sentidos dos discursos expressos nas classes.

\section{Resultados e Discussão}

O tratamento realizado pelo Alceste indicou a presença de cinco classes temáticas, divididas em dois grandes eixos. Um eixo reuniu os discursos relativos ao consumo de drogas, agrupando as classes 1 e 2, enquanto o outro eixo reuniu os discursos relativos ao tráfico do crack, agrupando as classes 3, 4 e 5 (Figura 1).

\section{Consumo: danos individuais e coletivos (Classes 1 e 2)}

As classes 1 (danos individuais) e 2 (danos coletivos) não estão diretamente relacionadas ao crack, na medida em que representam questões relativas às

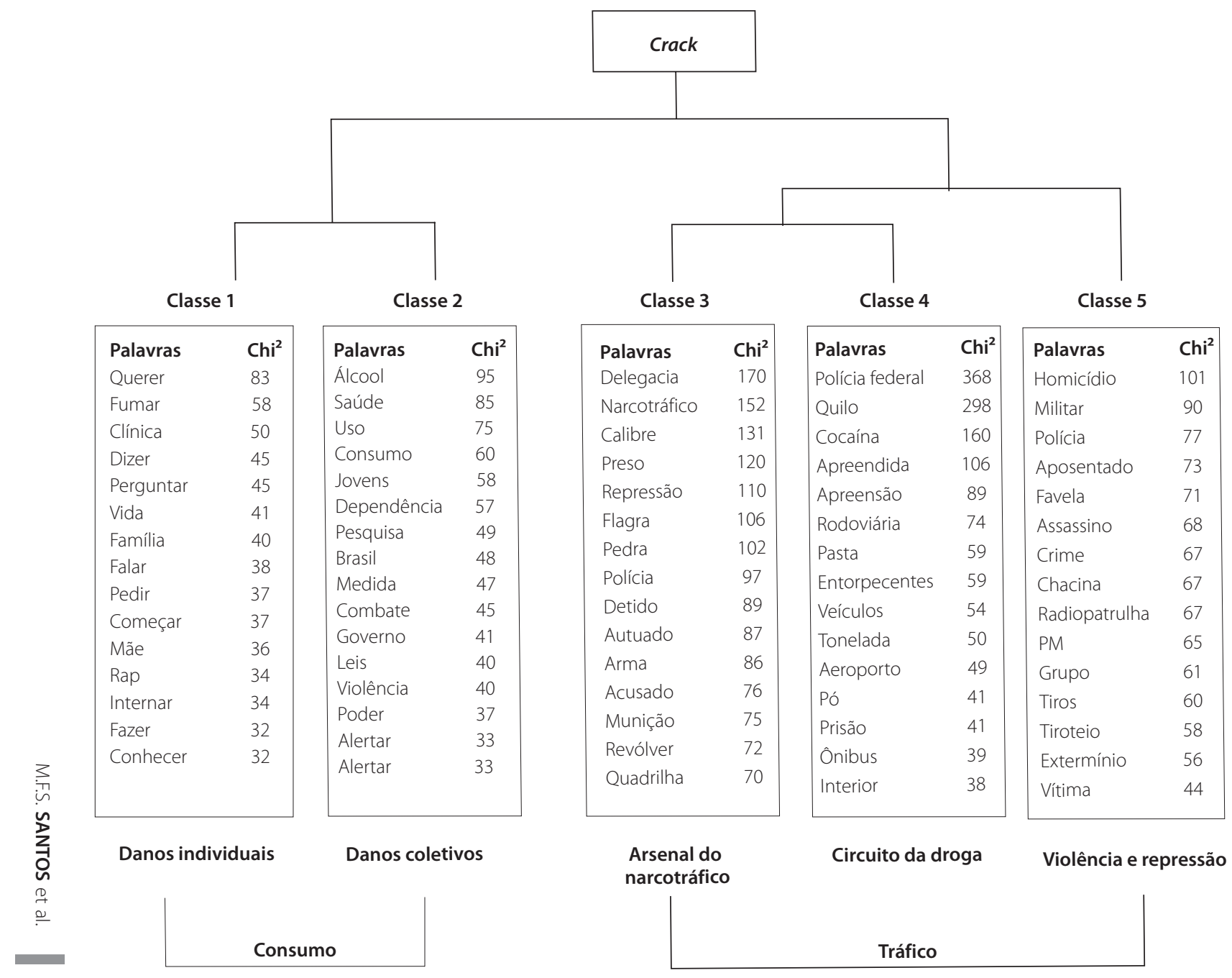

382 Figura 1. Dendrograma dos discursos sobre o crack produzidos pelos jornais. 
drogas em geral. Os conteúdos reunidos nessas classes, no entanto, remetem à droga como um problema individual e público, para o qual a sociedade deve ser alertada com o intuito de promover ações que amenizem suas consequências.

A classe 1 demonstra uma relação entre o consumo de psicoativos e o tratamento, ressaltando essa questão como uma preocupação de ordem individual e familiar. A dependência é mostrada como algo que leva a uma forte angústia, a partir da qual se busca um meio de ajuda, remetendo a uma necessidade de tratamento clínico, devido ao estado de fragilidade em que se encontra o usuário. A droga é associada à morte, e o internamento aparece como a possibilidade mais plausível de recuperação do dependente. O trecho abaixo é ilustrativo desse discurso:

Uma mãe acorrentou o filho de 15 anos, em Araraquara, para evitar que ele consumisse drogas e fosse morto por traficantes. O caso foi descoberto anteontem pelo Conselho Tutelar, acionado pela mulher, que contou tê-lo amarrado no dia anterior. ... O adolescente estava amarrado pelos pés e pelas mãos e que a corrente estava presa em uma grade no interior da casa. "Ela sofreu muito para fazer isso, mas foi um ato de desespero e amor" (Anonimos, 2008a).

Dessa forma, pode-se perceber que o consumo de uma substância psicoativa, mais especialmente o crack, corresponde a uma ideia em torno do sofrimento. Além disso, os mecanismos de ação da substância também geram a "síndrome de dependência" (Martin \& Hubbard, 2002), que se caracteriza por um repertório comportamental, no qual a"fissura" (craving) leva a uma necessidade incontrolável de consumo, sem necessariamente estar-se em presença de mudanças neurofisiológicas: a prioridade é a busca da droga. É esse o comportamento destacado pela imprensa.

A classe 2, interligada à classe 1 que reúne o discurso no qual a "droga" é pensada a partir do consumo, parece, entretanto, remeter a uma preocupação pública com os efeitos e consequências dessa atividade. Essa classe implica uma concepção do consumo como fator que necessita de atenção da população e, em especial, do Estado. Sendo assim, essa prática social deve ser prevenida por meio de políticas públicas e ações sociais que alertem para os riscos do abuso e ofereçam tratamento aos dependentes. Vale salientar que, em sua maioria, os discursos sobre o assunto são voltados para os psicoativos lícitos, como exemplificam os trechos a seguir:

Os conselheiros chegaram a conversar com o jovem, que negou ser viciado. Ao ser solto pela mãe a pedido do conselho, foi levado ao um pronto-socorro e, após exames, encaminhado a uma clínica de recuperação de dependentes químicos na região (Anonimos, 2008a).

Em matéria de dependência química, a nicotina é imbatível. Vicia mais que cocaína, heroína, crack, álcool, anfetamina ou qualquer droga já inventada. Em 40 anos de profissão, perdi a conta dos que sucumbiram às doenças causadas pelo fumo sem conseguir livrar-se dele, por mais que tenham tentado (Varela, 2007).

As discussões sobre as drogas tomaram uma dimensão muito ampla. Hoje, os debates são engendrados por discursos científicos que situam as drogas como problemas ora relacionados com a segurança pública, ora com a saúde pública (Garcia, Leal \& Abreu, 2008). Novamente, é importante ressaltar que, apesar de esses debates serem relativamente recentes, o uso das substâncias psicoativas não o é; segundo Soares e Jacobi (2000), esse é um fato presente em todas as sociedades. Tal dado, entretanto, não vem legitimar o uso nem ignorar os problemas a ele inerentes, mas assinala que quaisquer medidas cujo objetivo seja a extinção por completo da droga podem ser utópicas.

Nesse contexto, a partir da percepção de que o uso da droga poderia trazer consequências negativas para esferas tanto da saúde, como políticas e sociais, surgiu no mundo, e mais especificamente nos Estados Unidos, uma série de movimentos populares. Tais movimentos, que tinham forte cunho religioso, visavam estigmatizar usuários de drogas e eram carregados de concepções proibicionistas (MacRae, 2001). Posteriormente, no início do século XX, o próprio governo norte-americano passou a adotar essas ideias sob a forma de políticas públicas. A partir daí surgiram medidas que regulamentavam e visavam controlar os meios de produção das substâncias psicoativas por todo o mundo.

Nesse sentido, com o crescente desenvolvimento de posicionamentos estatais a respeito da droga, pode-se falar em políticas públicas. Como coloca Hofling (2001), as políticas públicas podem ser entendidas como o Estado em ação; é o Estado (entendido como conjunto de instituições que permitem a ação 
do governo) implantando um projeto de governo: programas e ações voltados para setores específicos da sociedade (Hofling, 2001). As políticas são, portanto, de responsabilidade do Estado, que as implementa e age de acordo com processos de tomada de decisão, para esse caso, sobre as questões da droga e tudo que a ela é vinculado. No entanto, como se pode perceber, os debates não são particulares de decisões políticas, mas ocorrem constantemente no cotidiano, dado o caráter social do tema.

\section{Tráfico: arsenal (Classe 3), circuito da droga (Classe 5), violência e repressão (Classes 4)}

A classe 3 associa o narcotráfico com o armamento, mas sem estabelecer as consequências desse "arsenal". Porém, essas armas somente aparecem quando relacionadas ao tráfico e sempre relacionadas a ações repressivas de cunho policial. As informações remetem a uma compreensão da droga como fator que leva ao armamento das pessoas envolvidas com psicoativos e, em seguida, à defesa da sociedade com a repressão. Este trecho ilustra essa situação:

Com Givaldo, foram encontrados uma espingarda calibre 12, uma pistola calibre 380 e um colete a prova de balas, alé de 220 papelotes de maconha, 75 pedras de crack pronta para consumo e uma pedra grande, com 20 gramas, que ainda seria dividida (Anonimos, 2008b).

A classe 5 , em continuidade, apresenta o tráfico através de suas etapas: a produção, o armazenamento e a distribuição da droga. O consumo, que conclui o circuito da "economia" em torno da droga, seria a última fase, que, por sua vez, não é abordada nessa classe. A política repressiva configura-se para prevenir que o consumo possa ser estabelecido, partindo do pressuposto de que a diminuição da oferta, pela proibição, terminaria por diminuir a demanda. No entanto, como assinalam Garcia et al. (2008), as políticas proibitivas não são eficazes para a redução do consumo e terminam por dificultar o seu controle e agravar determinados quadros de violência. Assim, as estratégias mencionadas pelos jornais coadunam-se com o processo de investigação e intervenção das atividades relacionadas com a "economia da droga", como pode ser observado no trecho abaixo:

Um laboratório de fabricação de crack foi descoberto na madrugada desta quarta-feira (18) pela Polícia Federal (PF), na Praia de Gaibu, no município do Cabo de Santo de Agostinho. O local foi encontrado depois que três pessoas foram presas nessa terça (17) em flagrante perto da rodoviária de Cupira, no Agreste do Estado, com 1,5kg de pasta base de coca, matéria prima para fabricação da droga. No laboratório, agentes da PF apreenderam mais $5 \mathrm{~kg}$ de crack (Anonimos, 2007a).

Sobre esse aspecto, deve ser ressaltado que a estigmatização das drogas ilícitas e de seus usuários atua como uma ferramenta eficaz para ordenar a sociedade (Bucher, 1996; Velho, 1987). No Brasil, existe regulamentação sobre entorpecentes desde 1938, tendo sido incorporada ao Código Penal posteriormente, em 1941. Esses primeiros registros legais revelam noções criminalizadoras do consumo de drogas. A partir da década de 1960, com alterações legislativas, as políticas antidrogas foram assumindo caráter explicitamente repressor, objetivando reduzir a oferta. Para isso, a solução era prender tanto traficantes como usuários; a ideia era restringir $\mathrm{O}$ acesso às drogas até chegar a sua extinção (Garcia et al., 2008).

Somente a partir da década de 1990, substituem-se os sistemas anteriores pelo Sistema Nacional Antidrogas. Um dos fatores que contribuíram para essa substituição foi a crescente adesão aos Princípios Diretivos de Redução da Demanda por Drogas. Assim, além dos aspectos ligados à repressão, abre-se espaço também para o tratamento e a reinserção social dos usuários (Garcia et al., 2008). Posteriormente, surge outra política pública relacionada às drogas, dessa vez situando-a como um problema de saúde pública. Assim, a política do Ministério da Saúde para atenção integral a usuários de álcool e outras drogas situa a sua proposta caminhando para uma política de redução de danos, tendo por objetivo não a abstinência do usuário, mas, acima disso, o respeito pela vida, descriminalizando-o e tornando-o sujeito ativo em suas relações com o mundo (Brasil, 2004).

Nesse contexto, as políticas públicas brasileiras, reformuladas nos últimos dez anos e aderentes à política redução de danos, não mais apresentam somente o viés repressivo, embora ainda estejam fortemente ligadas ao caráter proibitivo e de "luta" contra as drogas (Soares \& Jacobi, 2000). Tal quadro remete à preocupação com as interpretações que o conhecimento do senso comum tem a respeito da problemática envolvida com as drogas. De que forma tais políticas brasileiras mais recentes e suas implicações práticas são apreendidas pelos indivíduos em sociedade? Visto que a história do 
Brasil remonta a uma maior aderência a políticas de enfrentamento repressivo, é interessante pensar nessas produções de sentido no cotidiano para, inclusive, perceber quais tipos de ideologias circulam na sociedade, remetendo à eficácia real dessas políticas.

Essas informações estão em consonância com aquilo que caracteriza a classe 2, pois seriam reflexos da política adotada para combate às drogas. Fazendo uma comparação com as políticas antidrogas de outros países, Kopp (1998) descreve que a Holanda adota a iniciativa de diminuir os danos sociais causados pela droga, em oposição à política brasileira de diminuir a quantidade de consumidores. Essa ação visa à descriminalização da droga, com o intuito de evitar custos relativos à interdição e de reduzir a violência proveniente da busca por mercado.

A classe 4, por fim, demonstra a violência proveniente do narcotráfico: devido à repressão policial, cria-se uma "guerra" na qual a vítima é a sociedade - de um lado, as ações públicas de combate às drogas; de outro, o narcotráfico reagindo com a formação do crime organizado e desenvolvendo uma batalha "interna"entre os diferentes grupos, em busca de "mercado consumidor". Com esses conflitos, quem sofre as consequências é a sociedade, pois os reflexos dessa "guerra" implicam violência urbana e intranquilidade da população. A violência surge, seja através de atividades diretamente relacionadas com o tráfico, seja por conta de atos isolados de indivíduos em busca da droga. Além disso, essa classe sempre está associando a droga ao crack, como se essa substância, especificamente, estivesse em relação direta com a violência. O trecho abaixo demonstra isso:

Um rapaz identificado como George Washington da Silva, 20 anos, foi assassinado a tiros de pistola 380 na madrugada desta terça-feira (18) no bairro dos Coelhos, no Recife. No local, a polícia encontrou um cachimbo usado para fumar crack e dois tubos de lol (Anonimos, 2007b).

Essa classe reúne matérias nas quais se descrevem crimes ocorridos na cidade, retrata-se a violência urbana e supõe-se uma ligação entre violência e droga. Ora essa ligação é claramente expressa ao se noticiar uma briga entre traficantes que ocasiona a morte de pessoas inocentes, ora é um assassinato cuja motivação não é descrita, mas é insinuada na medida em que se explicita a apreensão de pedras de crack com o suspeito do crime.

\section{Considerações Finais}

Os dados analisados nesta pesquisa permitem afirmar que os jornais veiculam discursos sobre o crack que, por um lado, o descrevem como uma droga relacionada a uma forte angústia e fragilidade do sujeito, descrito como alguém que se torna incapaz de lutar contra seu estado de dependência, fazendo-se necessárias estratégias de tratamento baseadas na internação. Os jornais objetivam essa ideia em casos específicos, enfatizando a noção de morte ligada à dependência e a impossibilidade de saída sem o internamento. Além disso, de acordo com as reportagens, pode-se observar o surgimento de uma preocupação quanto aos efeitos dessa droga na sociedade, os quais devem ser prevenidos por meio de políticas públicas e ações sociais informativas sobre os riscos do consumo, assim como por meio de tratamento aos dependentes. Por outro lado, o crack é veiculado como parte do narcotráfico, relacionando-se com a criminalidade, expressa na produção clandestina da droga, no uso de armas pelos traficantes e na violência urbana provocada por suas ações.

Os sentidos construídos pela imprensa sobre o crack parecem ancorar-se na ideia de loucura e violência. Por um lado, o usuário é apresentado como alguém que está fora de si, fora da "normalidade". O crack é objetivado em determinados casos que destacam a impossibilidade de o sujeito fazer aquilo que deseja (livrar-se da dependência), as ideias de morte diante dessa impossibilidade e a necessidade de internamento. O usuário é assim aproximado do "louco". Por outro lado, além de um problema de saúde, o crack aparece como um problema de polícia. O crack é objetivado no tráfico e na violência, seja esta a praticada entre traficantes, seja a violência "natural" de um usuário.

Ao se situar o usuário como sujeito desprovido de capacidade avaliativa de sua própria condição e de sua relação com a droga, pode-se recair em práticas paternalistas e/ou violentas com os usuários. Além disso, as ações voltadas para essa questão podem situar o usuário de drogas a partir de lógicas criminalizantes, patologizantes e moralizantes. Resta muitas vezes ao sujeito que consome o crack, ainda que de forma implícita, o rótulo de criminoso, doente ou pecador. Essa repressão, muitas vezes, surge diretamente envolvida com o desenvolvimento e manutenção da violência urbana, consequente da "guerra contra as drogas". 
Por fim, esta pesquisa voltou-se a uma análise das representações sociais do crack nos jornais, mas o tema ainda necessita de outros estudos que complementem seus resultados. Buscou-se aqui compreender como esse fenômeno tem sido tratado na mídia impressa pernambucana, considerando-se que as representações sociais que nela circulam contribuem para a construção da forma de pensar a droga e seu usuário entre a população.

\section{Referências}

Almeida, A. M. (2005). Diálogos com a teoria das representações sociais. In M. F. S. Santos \& A. M. Almeida (Orgs.), A pesquisa em representações sociais: proposições teóricometodológicas (pp.118-159). Recife: UFPE.

Anônimos. (2007a, 18 de abril). PF descobre laboratório de crack em Gaibu e três são presos. Jornal do Comércio. Recuperado em julho 5, 2008, disponível em <http:// ne10.uol.com.br/canal/cotidiano/pernambuco/noticia/ 2007/04/18/pf-descobre-laboratorio-de-crack-emgaibu-e-tres-sao-presos-127989.php>.

Anônimos. (2007b, 18 de setembro). Jovem morto a tiros de pistola nos Coelhos. Jornal do Comércio. Recuperado em julho 5,2008, disponível em <http://ne10.uol.com.br/ canal/cotidiano/pernambuco/noticia/2007/09/18/ jovem-morto-a-tiros-de-pistola-nos-coelhos-39952.php>.

Anônimos. (2008a, 5 de janeiro). Mãe acorrenta filho de usuário de crack em Araraquara. Folha de São Paulo. Recuperado em julho 5, 2008, disponível em <http:// www1.folha.uol.com.br/fsp/cotidian/ff0501200828.htm>.

Anônimos. (2008b, 9 de abril). Homem é preso com armas e 220 papelotes de maconha. Jornal do Comércio. Recuperado em julho 5, 2008 , disponível em <http:// ne10.uol.com.br/canal/cotidiano/pernambuco/noticia/ 2008/04/09/homem-e-preso-com-armas-e-220papelotes-de-maconha-154886.php>.

Brasil. Ministério da Saúde. (2004). A política do Ministério da Saúde para atenção integral a usuários de álcool e outras drogas. Brasília: MS.

Bucher, R. (1996). Drogas e sociedade nos tempos de Aids. Brasília: UnB.

Bucher, R., \& Lucchini, R. (1992). Drogas e drogadição no Brasil. In R. Bucher (Org.), À procura de uma abordagem multidisciplinar da toxicomania. Porto Alegre: Artmed.

Carlini, E. A., Galduróz, J. C., Noto, A. R., Carlini, C. M., Oliveira, L. G., Nappo, S. A., et al. (2007). I/ Levantamento domiciliar sobre ouso de drogas psicotrópicas no Brasil:estudo envolvendo as 108 maiores cidades do país. São Paulo: CEBRID.

Duailibi, L. B., Ribeiro, M., \& Laranjeira, R. (2008). Profile of cocaine and crack users in Brazil. Cadernos de Saúde Pública, 24 (4), 545-557.

Ferreira, P. E. M., \& Martini, R. K. (2001). Cocaína: lendas, história e abuso. Revista Brasileira de Psiquiatria, 23 (2), 96-99. Recuperado em junho 12, 2010, disponível em <http://www.scielo.br>. doi: 10.1590/S1516-44462001 000200008 .
Galduróz, J. C. F., Noto, A. R., \& Carlini, E. A. (1997). IV Levantamento sobre o uso de drogas entre estudantes de 10 e $2^{\circ}$ graus em 10 capitais brasileiras. São Paulo: CEBRID.

Galduróz, J. C. F., Noto, A. R., Fonseca, A. M., \& Carlini, E. A. (2005). V Levantamento nacional sobreo consumo de drogas psicotrópicas entre estudantes do ensino fundamental e médio da rede pública de ensino nas 27 capitais brasileiras. São Paulo: CEBRID.

Garcia, M. L. T., Leal, F. X., \& Abreu, C. C. (2008). A política antidrogas brasileira: velhos dilemas. Psicologia e Sociedade, 20 (2), 267-276. Recuperado em julho 13, 2010, disponível em <http://www.scielo.br>. doi: 10.1590/S0 102-71822008000200014.

Hofling, H. M. (2001). Estado e políticas (públicas) sociais. Cadernos Cedes, 21 (55), 30-41.

Jodelet, D. (2001). Representações sociais: um domínio em expansão. In D. Jodelet (Org.), Representações sociais (pp.17-44). Rio de Janeiro: EdUERJ.

Kopp, P. (1998). Avaliação das políticas públicas antidrogas In P. Kopp (Org.), A economia da droga (pp.183-242). Bauru: EDUSC.

Martin. P. R. \& Hubbard, J. R. (2002). Transtornos relacionados a substâncias. In M.H. Ebert, P.T. Loosen \& B. Nurcombe (Orgs.), Psiquiatria: diagnóstico e tratamento (pp.233-258). Porto Alegre: Artmed.

MacRae, E. (2001). Antropologia: aspectos sociais, culturais e ritualísticos. In S. D. Seibel \& A. Toscano Jr. (Orgs.), Dependência de drogas (pp.25-34). São Paulo: Atheneu.

Moscovici, S. (2003). Representações sociais: investigações em psicologia social. In S. F. Neiva (Org.), O fenômeno das representações sociais. (pp.29-110). Petrópolis: Vozes.

Nascimento, A. R. A., \& Menandro, P. R. M. (2006). Análise lexical e análise de conteúdo: uma proposta de utilização conjugada. Estudos e Pesquisas em Psicologia, 6 (2), 72-88.

Oliveira, L. R. (2007). Avaliação da cultura do uso de crack após uma década de introdução da droga na cidade de São Paulo. Tese de doutorado não-publicada, Universidade Federal de São Paulo.

Oliveira, L. R., \& Nappo, A. S. (2008). Caracterização da cultura de crack na cidade de São Paulo: padrão de uso controlado. Revista de Saúde Pública, 42 (4), 664-671.

Santos, M. F. S. (2005). Diálogos com a teoria das representações sociais. In M. F. S. Santos \& A. M. Almeida (Orgs.), A teoria das representações sociais (pp.118-159). Recife: UFPE.

Soares, C. B., \& Jacobi, P. R. (2000). Adolescentes, drogas e AIDS: avaliação de um programa de prevenção escolar. Cadernos de Pesquisa, (109), 213-37.

Toscano Jr., A. (2001). Um breve histórico sobre o uso de drogas. In S. D. Seibel \& A. Toscano Jr. (Orgs.), Dependência de drogas (pp.7-23). São Paulo: Atheneu.

United Nations Office on Drugs and Crime. (2011). World drug report 2011. New York: United Nations.

Varela, D. (2007, 18 de agosto). Crime e castigo. Folha de São Paulo. Recuperado em julho 5, 2008, disponível em <http://www1.folha.uol.com.br/fsp/ilustrad/fq1808200 729.htm>.

Velho, G. (1987). Individualismo e cultura. In G. Velho (Org.), Duas categorias de acusação na cultura brasileira contemporânea (pp.55-64). Rio de Janeiro: Zahar.

Recebido em: 10/1/2011

Aprovado em: 21/12/2011 